\title{
Efektivitas Program Aquatic Exercise Terhadap Fleksibilitas Lumbal Pasien Chronic Low Back Pain \\ ${ }^{1} \bowtie$ Arif Pristianto, ${ }^{2}$ Aulia Ayu Kusuma Wardani, ${ }^{3}$ Widya Ervianta, ${ }^{4}$ Totok Budi Santoso \\ ${ }^{1,2,4}$ Program Studi Fisioterapi, Fakultas Ilmu Kesehatan, Universitas Muhammadiyah Surakarta, ${ }^{3} \mathrm{RST}$ dr. Soedjono Magelang \\ Jl. A. Yani Tromol Pos I Pabelan Kartasura Telp. (0271) 717417 Fax. (0271) 715448 Surakarta 57162 \\ $\bowtie$ Email : arif.pristianto@ums.ac.id
}

Tanggal Submisi: 16 Desember 2020; Tanggal Penerimaan: 29 Desember 2020

\begin{abstract}
ABSTRAK
Chronic low back pain (CLBP) dapat mempengaruhi perubahan postur dan mengurangi kekuatan otot yang dihasilkan dan dapat menyebabkan berkurangnya fleksibilitas tulang belakang. Aquatic exercise telah digunakan selama bertahun-tahun dalam mengelola masalah muskuloskeletal termasuk low back pain.

Tujuan: Mengetahui efektivitas program aquatic exercise terhadap peningkatan fleksibilitas lumbal pada pasien chronic low back pain di RST dr. Soedjono Magelang.

Metode: Jenis penelitian yang digunakan adalah Quasi Experimental Design dengan pendekatan One Group Pre-Test dan Post-Test. Teknik pengambilan sampel dalam penelitian ini menggunakan purposive sampling. Jumlah sampel sebanyak 11 orang.

Hasil: Hasil Uji Paired Sample t-Test rata-rata pengukuran fleksibilitas lumbal sebelum dan sesudah perlakuan sebesar $1,7091 \mathrm{~cm}$ dan 2,3091 cm. Hasil uji statistik diperoleh p adalah 0,001.

Kesimpulan: Aquatic exercise efektif terhadap peningkatan fleksibilitas lumbal pasien chronic low back pain pada RST dr. Soedjono Magelang.
\end{abstract}

Kata kunci: chronic low back pain, aquatic exercise, fleksibilitas lumbal, lower cross syndrome, daya apung.

\section{ABSTRACT}

Chronic low back pain (CLBP) can affect changes in posture and reduce the strength of the muscles produced and can cause reduced spinal flexibility. Aquatic exercise has been used for many years in managing musculoskeletal problems including low back pain.

Objectives: To determine the effectiveness of the aquatic exercise program to increase lumbar flexibility in chronic low back pain patients in RST dr. Soedjono Magelang.

Methods: The type of research used is Quasi Experimental Design with One Group Pre-Test and PostTest approaches. The sampling technique in this study used purposive sampling. The number of samples is 11 people.

Results: Paired Sample t-Test Results, the average measurement of lumbar flexibility before and after treatment was $1.7091 \mathrm{~cm}$ and $2.3091 \mathrm{~cm}$. The statistical test results obtained $\mathrm{p}$ is 0.001 .

Conclusion: Aquatic exercise is effective against increasing the lumbar flexibility of chronic low back pain patients on RST dr. Soedjono Magelang.

Keywords: chronic low back pain, aquatic exercise, lumbar flexibility, lower cross syndrome, buoyancy.

\section{Pendahuluan}

Low back pain (LBP) didefinisikan sebagai rasa sakit dan ketidaknyamanan yang terletak diantara tulang rusuk dan gluteal, rasa sakit juga dapat muncul pada kaki (Macedo et al., 2016). Low back pain (LBP) biasanya 
diklasifikasikan sebagai 'specific' atau 'nonspecific' (Middelkoop et al., 2010). Menurut Dheka (2018) Low back pain dapat dikelompokkan ke dalam tiga kategori: akut, subakut, dan kronis. Chronic low back pain (CLBP) didefinisikan sebagai rasa sakit punggung bawah yang berlangsung lebih dari 12 minggu (Boer \& Tulder, 2013). Keluhan low back pain dapat mempengaruhi perubahan postur dan mengurangi kekuatan otot yang dihasilkan. Kelelahan otot dapat menyebabkan berkurangnya fleksibilitas tulang belakang, sehingga mempengaruhi mobilitas lumbal saat fleksi ke depan dan lateral bending (Vismara et al., 2010). Fatoni et al. (2012) menyebutkan faktor resiko terjadinya low back pain antara lain usia, obesitas, indeks massa tubuh, kehamilan dan faktor psikologi.

Muscle imbalance terjadi ketika panjang atau kekuatan otot agonis dan antagonis membatasi fungsi normal. Misalnya, ketegangan m. Hamstring dapat membatasi gerakan full ROM dan kekuatan hip extention (Maffetone, 2010). Kinematika dari lower extremity dapat berubah sebagai akibat dari lemahnya kekuatan otot panggul (Prins \& Wurff, 2009). Lower cross syndrome merupakan kelainan pada otot postural dengan penurunan fleksibilitas, pemendekan otot panggul dan otot ekstensor, dapat menyebabkan tambahan penekanan pada sendi dan jaringan lunak tulang belakang, dan dapat menyebabkan lumbal lordosis (Gordon \& Bloxham, 2016). Lower cross syndrome terjadi karena adanya kelemahan otot pada $m$. abdominals dan $m$. gluteus maximus serta ketegangan otot pada $m$. iliopsoas dan erector spine (Dhanani \& Shah, 2014).

Menurut penelitian The Global Burden of Low Back Pain tahun 2010, prevalensi titik standar global usia Low Back Pain (dari 0 hingga 100 tahun) pada tahun 2010 diperkirakan 9.4\%, lebih tinggi pada laki-laki (rata-rata: 10.1\%; 95\%) dibandingkan dengan perempuan (rata-rata: $8.7 \%$;
95\%). Nyeri punggung bawah diderita usia muda maupun tua namun semakin parah pada usia 3060 tahun ke atas.

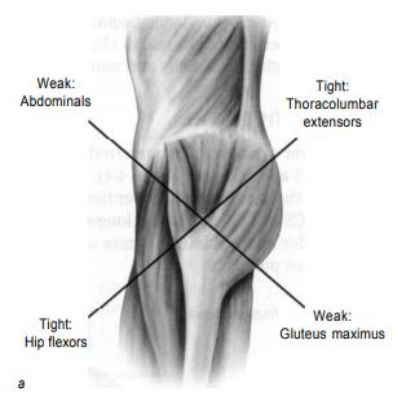

Gambar 1. Lower Cross Syndrome (Goleman et al., 2019)

Menurut Waller et al. (2009) aquatic exercise telah digunakan selama bertahun-tahun dalam mengelola masalah muskuloskeletal termasuk low back pain. Melalui efek daya apung, memungkinkan kinerja gerakan yang biasanya sulit dilakukan di darat menjadi mudah dilakukan di dalam air. Penelitian sebelumnya yang dilakukan Em et al. (2016) telah mendapatkan hasil dengan durasi di air selama 12 minggu, mereka menunjukkan bahwa aquatic exercise menghasilkan peningkatan jangka pendek yang kecil dibandingkan dengan mengontrol rasa sakit.

Gerakan aquatic exercise yang digunakan dalam penelitian mencakup Stretching, Strengthening, Stabilization, Pelvic Tilt. Terapi dilaksanakan dengan dosis:
- Frequency : 2 kali dalam seminggu selama 3 minggu
- Intensity $: 2-3$ pengulangan
dengan 60 detik istirahat
pada setiap gerakan
- Time :30-60 menit
- Type : stretching, strengthening, stabilization

Peregangan (stretching) memiliki salah satu efek utama yaitu untuk meningkatkan fleksibilitas otot dan jaringan tulang belakang, 
latihan stabilisasi memiliki efek untuk mengembalikan kontrol motorik otot-otot trunk (França et al., 2012). Gerakan stretching meliputi Cervical spine: flexion, lateral flexion, Thoracic and lumbar spine: lateral flexion/side bending, Hip stretching: hip extension, hip external rotation, hip internal rotation, Knee stretching: hamstring stretch.

Strengthening digunakan untuk memperkuat otot pada daerah abdomen, lumbal, pelvis sehingga otot-otot tersebut akan berkontraksi untuk mengatur postur lumbal (Nath et al., 2013). Gerakan strengthening meliputi Extremity strengthening: Shoulder internal and external rotation, Elbow flexion and extension, Hip extension and extension, Functional squating, and Ankle plantar flexion. Tekanan hidrostatik pada saat di dalam air memberikan tahanan pada saat bergerak, hal ini menimbulkan peningkatan kekuatan otot (Yuniarwati, 2013). Adapula gerakan Dynamic trunk stabilization: frontal plane, multidirectional, dan Pelvic tilt.

Penelitian ini bertujuan untuk melihat pengaruh dari gerakan-gerakan latihan yang dilakukan di dalam air terhadap peningkatan fleksibilitas otot pada area lumbal pada pasien chronic low back pain.

\section{Metode Penelitian}

Penelitian dilaksanakan di RST dr. Soedjono Magelang. Adapun waktu penelitian ini tanggal 17 Desember 2019 sampai 16 Januari 2020. Jenis penelitian adalah Quasi Experimental Design. Desain penelitian dalam penelitian ini adalah One Group Pre-Test dan Post-Test. Jumlah sampel yang diteliti berjumlah 11 orang. Variabel bebasnya adalah aquatic exercise. Variabel terikatnya adalah fleksibilitas lumbal penderita chronic low back pain.

\section{Hasil}

Penelitian yang dilakukan pada 11 orang pasien dengan keluhan chronic low back pain di RST dr. Soedjono Magelang didapatkan hasil adanya peningkatan fleksibilitas pada regio lumbal setelah diberikan program aquatic exercise. Dalam penelitian ini sebaran pasien berdasarkan jenis kelamin diperoleh data 3 lakilaki dan 8 perempuan dengan rentang usia $30-65$ tahun.

\begin{tabular}{lcccccc}
\multicolumn{7}{c}{ Tabel 1. Data Karakteristik } \\
\hline Nama & $\begin{array}{c}\text { Jenis } \\
\text { Kelamin }\end{array}$ & Umur & Pekerjaan & $\begin{array}{c}\text { BB } \\
(\mathbf{k g})\end{array}$ & $\begin{array}{c}\text { TB } \\
(\mathbf{c m})\end{array}$ & IMT \\
\hline Bp M & Laki-laki & 65 & Pensiunan & 67 & 159 & 26,5 \\
Bp AN & Laki-laki & 36 & TNI & 70 & 168 & 24,8 \\
Bp W & Laki-laki & 50 & PNS & 58 & 160 & 22,65 \\
Ibu D & Perempuan & 65 & IRT & 72 & 154 & 30,35 \\
Ibu TS & Perempuan & 65 & IRT & 58 & 148 & 26,47 \\
Ibu SAB & Perempuan & 62 & IRT & 65 & 146 & 30,49 \\
Ibu SW & Perempuan & 49 & IRT & 52 & 156 & 21,36 \\
Ibu NM & Perempuan & 45 & IRT & 65 & 155 & 27,05 \\
Ibu S & Perempuan & 49 & IRT & 66 & 150 & $29,3\}$ \\
Ibu LE & Perempuan & 50 & IRT & 63 & 148 & 28,76 \\
Ibu DPA & Perempuan & 52 & Pensiunan & 54 & 153 & 23,06 \\
\hline Mean & & 53,54 & & 62,72 & 154,27 & 26,43 \\
\hline
\end{tabular}

Tabel 2. Uji Normalitas

\begin{tabular}{cccc}
\hline \multirow{2}{*}{ Perlakuan } & \multicolumn{3}{c}{ Shapiro-Wilk } \\
\cline { 2 - 4 } & Statistic & df & Sig. \\
\hline Pretest & 0,951 & 11 & 0,651 \\
Posttest & 0,974 & 11 & 0,924 \\
\hline
\end{tabular}

Data hasil tabel 2 didapatkan bahwa uji normalitas dengan Shapiro-Wilk Test mendapatkan hasil data yang berdistribusi normal.

Tabel 3. Uji Pengaruh

\begin{tabular}{lllll}
\hline & $\begin{array}{c}\text { Mean } \\
\text { Fleksibilitas } \\
\text { Lumbal }\end{array}$ & n & $\begin{array}{c}\text { Std. } \\
\text { Deviation }\end{array}$ & Sig. \\
\hline Pretest & 1.71 & 11 & 0.94388 & 0.001 \\
Posttest & 2.31 & 11 & 0.87230 & \\
\hline
\end{tabular}


Pada penggunaan Uji Paired Sample tTest mengidentifikasikan pengaruh sebelum dan sesudah pemberian perlakuan pada responden. Berdasarkan tabel di atas, rata-rata pengukuran fleksibilitas lumbal sebelum dan sesudah perlakuan sebesar $1,71 \mathrm{~cm}$ dan $2,31 \mathrm{~cm}$.

\section{Pembahasan}

Tingkat resiko keluhan otot rangka dapat dipengaruhi oleh jenis kelamin, secara fisiologis, pria memiliki kemampuan otot yang lebih tinggi dibanding wanita (Andini, 2015). Pada laki-laki memiliki bahu yang lebar, pusat gravitasi yang lebih tinggi, dan otot yang lebih besar serta kaku dibandingkan dengan perempuan. Hal tersebut juga mempengaruhi terhadap perbedaan dalam adaptasi jaringan dan pola pergerakan (Sahrmann, 2011). Berdasarkan hasil data penelitian, jenis kelamin yang sering mengalami chronic low back pain adalah perempuan sebanyak 8 orang (72,72\%).

Pada usia 58-65 tahun berjumlah 4 orang $(36,37 \%)$ dan dapat disimpulkan mayoritas yang mengalami chronic low back pain berusia antara 58-65 tahun. Pada survei di Inggris menunjukkan bahwa prevalensi konsultasi tahunan untuk chronic low back pain adalah 417 per 10.000 pasien yang terdaftar dan tingkat tertinggi pada kelompok usia 45-64 tahun (536 dari 10.000) (Balagué et al., 2012).

Menurut Gupta \& Nandini (2015) menunjukkan bahwa $83 \%$ dari ibu rumah tangga pedesaan yang tidak bekerja memiliki low back pain dan pembatasan aktivitas karena rasa sakit serta dapat menyebabkan kelemahan dan kejang otot. Terlepas dari masalah medis lainnya, kehamilan dan persalinan memperburuk komplikasi pada wanita. Karakteristik pekerjaan responden yang memiliki chronic low back pain sebanyak 7 orang $(63,63 \%)$ bekerja sebagai ibu rumah tangga.

Jaringan lemak lebih banyak daripada jaringan otot pada orang gemuk sehingga memiliki kemampuan yang lebih sedikit untuk memproduksi energi (Lubis et al., 2015). Karakteristik IMT responden untuk chronic low back pain paling banyak terdapat pada kelompok cenderung obesitas yang berjumlah 7 orang $(63,64 \%)$.

Menurut daSilva et al. (2013) aquatic exercise memiliki efek penghilang rasa sakit bagi pasien dengan kondisi neurologis atau muskuloskeletal. Rasa hangat dan daya apung air dapat memfasilitasi relaksasi otot, menghalangi nosiosepsi dengan bekerja pada reseptor termal dan reseptor mekanik, sehingga mempengaruhi mekanisme segmental tulang belakang telah direkomendasikan untuk menurunkan nyeri punggung dan tidak ada uji coba yang menilai bahwa aquatic exercise memiliki efek yang merugikan (Kamioka et al., 2011). Aquatic exercise memiliki efek jangka pendek yang kecil tetapi signifikan secara statistik pada penyakit locomotor misalnya, arthritis, rheumatoid diseases, dan low back pain (Kamioka et al., 2010).

Penelitian sebelumnya yang dilakukan Baena et al. (2014) mendapatkan hasil program aquatic therapy selama dua bulan dengan frekuensi tinggi (lima kali/minggu) mengurangi tingkat nyeri punggung dan kecacatan, meningkatkan kualitas hidup, meningkatkan komposisi tubuh dan kebugaran tubuh yang berhubungan dengan kesehatan pada orang dewasa yang tidak aktif dengan chronic low back pain. Program aquatic exercise pada water-based exercise memberikan peningkatan yang lebih baik dalam kecacatan dan kualitas hidup pasien chronic low back pain dibanding dengan landbased exercise (Dundar et al., 2009).

Proses aquatic exercise dapat mempengaruhi fleksibilitas lumbal pada pasien chronic low back pain karena tekanan alami air membantu memperkuat otot. Efek tahanan air, dapat meningkatkan pengeluaran energi dan mengurangi beban mekanik pada ekstremitas 
bawah. Daya apung (buoyancy) mengurangi tekanan pada tulang, sendi dan otot yang memfasilitasi gerakan, dan dapat menghalangi nosiosepsi dengan bekerja pada reseptor termal dan reseptor mekanik, sehingga dapat mempengaruhi mekanisme segmental tulang belakang (Verhagen et al., 2012).

Aquatic exercise, tekanan hidrostatis, dan turbulence yang ada di air dapat berguna dalam meningkatkan kekuatan otot. Gaya apung dapat mengurangi beban tubuh dan dapat sebagai tahanan (Utomo et al., 2015). Gerakan dan aktivitas fungsional lebih nyaman di air karena tarikan gravitasi pada tubuh tidak sekuat di darat. Air mendukung tubuh, mengurangi tekanan sendi, dan memberikan resistensi dan bantuan untuk melakukan gerakan, memungkinkan peningkatan mobilitas, kekuatan dan fungsi tubuh (Henley \& Wollam, 2009).

Peregangan (stretching) memiliki salah satu efek utama yaitu untuk meningkatkan fleksibilitas otot dan jaringan tulang belakang, latihan stabilisasi memiliki efek untuk mengembalikan kontrol motorik otot-otot trunk (França et al., 2012). Gerakan stretching dalam program ini meliputi Cervical spine: flexion, lateral flexion, Thoracic and lumbar spine: lateral flexion/side bending, Hip stretching: hip extension, hip external rotation, hip internal rotation, Knee stretching: hamstring stretch.

Strengthening digunakan untuk memperkuat otot pada daerah abdomen, lumbal, pelvis sehingga otot-otot tersebut akan berkontraksi untuk mengatur postur lumbal (Nath et al., 2013). Gerakan strengthening meliputi Extremity strengthening: Shoulder internal and external rotation, Elbow flexion and extension, Hip extension and extension, Functional squating, and Ankle plantar flexion. Tekanan hidrostatik pada saat di dalam air memberikan tahanan pada saat bergerak, hal ini menimbulkan peningkatan kekuatan otot (Yuniarwati, 2013). Adapula gerakan Dynamic trunk stabilization: frontal plane, multidirectional, dan Pelvic tilt.

Obesitas juga berkontribusi besar terhadap kondisi low back pain (Irandoust \& Taheri, 2015). Hasil penelitian ini tidak mutlak, karena responden masih dibantu medikamentosa untuk mengurangi nyerinya, sehingga fleksibilitas lumbal responden bisa semakin meningkat. Pada penelitian Triasari \& Taslim (2017) adanya penurunan nyeri karena konsumsi obat pereda nyeri yaitu prednisolone, eperisone hydrochloride juga merupakan obat untuk meredakan rasa sakit, kaku, dan tegang otot (Rabbani et al., 2017).

Penelitian ini tentunya memiliki beberapa

keterbatasan antara lain dari segi variatif wilayah responden yang berhubungan dengan jumlah responden dan aktifitas masing-masing serta intervensi pembanding. Hal ini tentunya dapat menjadi masukan bagi penelitian lebih lanjut. Dalam penerapannya tentunya mempertimbangkan aspek individual pada masing-masing pasien yang mungkin dapat berbeda-beda.

\section{Kesimpulan}

Kesimpulan dari penelitian yang telah dilakukan adalah program aquatic exercise efektif terhadap peningkatan fleksibilitas lumbal pasien chronic low back pain (CLBP).

\section{Daftar Pustaka}

Andini, F. (2015). Risk Factors of Low Back Pain in Workers. Workers J Majority, 4(1), 1219.

Baena-Beato, P. Á., Artero, E. G., ArroyoMorales, M., Robles-Fuentes, A., GattoCardia, M. C., \& Delgado-Fernández, M. (2014). Aquatic Therapy Improves Pain, Disability, Quality of Life, Body 
Composition and Fitness in Sedentary Adults with Chronic Low Back Pain. A Controlled Clinical Trial. Clinical Rehabilitation, 28(4), 350-360. https://doi.org/10.1177/0269215513504943

Balagué, F., Mannion, A. F., Pellisé, F., \& Cedraschi, C. (2012). Non-Specific Low Back Pain. The Lancet, 379(9814), 482-491. https://doi.org/10.1016/S01406736(11)60610-7

Boer, M. R. De, \& Tulder, M. W. Van. (2013). Spinal Manipulative Therapy for Acute. Spinal Manipulative Therapy for Chronic Low-Back Pain (Review), 38(3), 158-177. https://doi.org/10.1097/BRS.0b013e31827d d89d

DaSilva, J. R., Borges, P. S., Agra, K. F., Pontes, I. A., \& Alves, J. G. B. (2013). Effects of an Aquatic Physical Exercise Program on Glycemic Control and Perinatal Outcomes of Gestational Diabetes: Study Protocol for A Randomized Controlled Trial. Trials, 14(1), 1-5. https://doi.org/10.1186/17456215-14-390

Dhanani, S., \& Shah, D. T. (2014). A Survey on Prevalence of Lower Crossed Syndrome in Young. 1(4), 142-157.

Dundar, U., Solak, O., Yigit, I., Evcik, D., \& Kavuncu, V. (2009). Clinical Effectiveness of Aquatic Exercise to Treat Chronic Low Back Pain: A Randomized Controlled Trial. Spine, 34(14), 1436-1440. https://doi.org/10.1097/BRS.0b013e3181a79 618

Em, B., Cb, J., Christensen, R., Kb, H., Dagfinrud, H., \& Lund, H. (2016). Aquatic Exercise for The Treatment of Knee and Hip Osteoarthritis ( Review ) Summary Of Findings for The Main Comparison. The Cochrane Collaboration, (3). https://doi.org/10.1002/14651858.CD00552 3.pub3.www.cochranelibrary.com

Fatoni, H., \& Swasti, K. G. (2012). Hubungan
Sikap dan Posisi Kerja dengan Low Back Pain pada Perawat RSUD Purbalingga. Soedirman Journal of Nursing, 7(2), 86-92.

França, F. R., Burke, T. N., Caffaro, R. R., Ramos, L. A., \& Marques, A. P. (2012). Effects of Muscular Stretching and Segmental Stabilization on Functional Disability and Pain In Patients with Chronic Low Back Pain: A Randomized, Controlled Trial. Journal of Manipulative and Physiological Therapeutics, 35(4), 279-285. https://doi.org/10.1016/j.jmpt.2012.04.012

Goleman, daniel; boyatzis, Richard; Mckee, A. (2019). Assessment and Treatment of Muscle Imbalance. In Journal of Chemical Information and Modeling (Vol. 53). https://doi.org/10.1017/CBO9781107415324 .004

Gordon, R., \& Bloxham, S. (2016). A Systematic Review of the Effects of Exercise and Physical Activity on Non-Specific Chronic Low Back Pain. Healthcare, 4(2), 22. https://doi.org/10.3390/healthcare4020022

Gupta, G., \& Nandini, N. (2015). Prevalence of Low Back Pain In Non Working Rural Housewives of Kanpur, India. International Journal of Occupational Medicine and Environmental Health, 28(2), 313-320. https://doi.org/10.13075/ijomeh.1896.00299

Henley, C., \& Wollam, K. (2009). Benefits and Techniques of Aquatic Therapy. Post-Polio Health International, 57-62. Retrieved from http://www.mixers.com/insights/mti_35.pdf

Irandoust, K., \& Taheri, M. (2015). The Effects of Aquatic Exercise on Body Composition and Nonspecific Low Back Pain In Elderly Males. Journal of Physical Therapy Science, 27(2), 433-435. https://doi.org/10.1589/jpts.27.433

Kamioka, H., Tsutani, K., Okuizumi, H., Mutoh, Y., Ohta, M., Handa, S., ... Honda, T. (2010). Effectiveness of Aquatic Exercise and Balneotherapy: A Summary of Systematic Reviews Based on Randomized 
Controlled Trials of Water Immersion Therapies. Journal of Epidemiology, 20(1), $2-12$.

https://doi.org/10.2188/jea.JE20090030

Kamioka, H., Tsutani, K., Okuizumi, H., Mutoh, Y., Ohta, M., Handa, S., ... Moriyama, S. (2011). A Systematic Review of Nonrandomized Controlled Trials on The Curative Effects of Aquatic Exercise. International Journal of General Medicine, 20(1), 239.

https://doi.org/10.2147/ijgm.s17384

Lia Dheka Arwino. (2018). Keluhan Nyeri Punggung Bawah pada Penjahit Garmen. Higeia Journal Of Public Health Research And Development, 2(3), 407.

Lubis, H. M., \& Sulastri, D. (2015). Hubungan Indeks Massa Tubuh dengan Ketahanan Kardiorespirasi, Ketahanan dan Kekuatan Otot dan Fleksibilitas Pada Mahasiswa LakiLaki Jurusan Pendidikan Dokter Universitas Andalas Angkatan 2013. Jurnal Kesehatan Andalas, 4(1), 142-150.

Macedo, L., Saragiotto, B., Yamato, T., Costa, L., Menezes Costa, L., Ostelo, R., \& Maher, C. (2016). Motor Control Exercise for Acute Non-Specific Low Back Pain (Review). Cochrane Database of Systematic Reviews, (2), 64. https://doi.org/10.1002/14651858.CD01208 5.www.cochranelibrary.com

Maffetone, P. (2010). The Assessment and Treatment of Muscular Imbalance - The Janda Approach. In Journal of Bodywork and Movement Therapies (Vol. 14). https://doi.org/10.1016/j.jbmt.2009.11.003

Nath, K., Jajoo, A., Poudyal, R. S., Timilsina, R., Park, Y. S., Aro, E. M., ... Lee, C. H. (2013). Towards A Critical Understanding of The Photosystem II Repair Mechanism and Its Regulation During Stress Conditions. FEBS Letters, 587(21), 3372-3381. https://doi.org/10.1016/j.febslet.2013.09.015
Prins, M. R., \& van der Wurff, P. (2009). Females with Patellofemoral Pain Syndrome Have Weak Hip Muscles: A Systematic Review. Australian Journal of Physiotherapy, 55(1), 9-15. $\quad$ https://doi.org/10.1016/S00049514(09)70055-8

Rabbani, G., Baig, M. H., Lee, E. J., Cho, W. K., Ma, J. Y., \& Choi, I. (2017). Biophysical Study on the Interaction between Eperisone Hydrochloride and Human Serum Albumin Using Spectroscopic, Calorimetric, and Molecular Docking Analyses. Molecular Pharmaceutics, 14(5), 1656-1665. https://doi.org/10.1021/acs.molpharmaceut.6 b01124

Triasari, T., Pinzon, R. T., Universitas, F., Dharma, S., Kedokteran, F., Kristen, U., \& Wacana, D. (2017). The Use of Methylprednisolone As a Pain Reliever in Acute Low Back Pain Patients At Ambulatory Department. Berkala Ilmiah Kedokteran Duta Wacana, 2(September), 467-476.

Utomo, B., Sukadarwanto, \& Syatibi, M. M. (2015). Peningkatan Kecepatan Jalan dan Keseimbangan Usia Lanjut Menggunakan Model Aquatik Exercise dan Land Exercise Therapy. Jurnal Terpadu Ilmu Kesehatan, 4(2), 82-89.

Van Middelkoop, M., Rubinstein, S. M., Verhagen, A. P., Ostelo, R. W., Koes, B. W., \& van Tulder, M. W. (2010). Exercise Therapy for Chronic Nonspecific Low-Back Pain. Best Practice And Research: Clinical Rheumatology, 24(2), 193-204. https://doi.org/10.1016/j.berh.2010.01.002

Verhagen, A. P., Cardoso, J. R., \& BiermaZeinstra, S. M. A. (2012). Aquatic Exercise \& Balneotherapy in Musculoskeletal Conditions. Best Practice and Research: Clinical Rheumatology, 26(3), 335-343. https://doi.org/10.1016/j.berh.2012.05.008

Vismara, L., Francesco, M., Zaina, F., Galli, M., Negrini, S., \& Capodoglio, P. (2010). Effect 
Of Obesity and Low Back Pain on Spinalmobility. Journal of NeuroEngineering and Rehabilitation, 3(7), $1-8$.

Waller, B., Lambeck, J., \& Daly, D. (2009). Clinical Rehabilitation. Clinical Rehabilitation, 23, 3-14. https://doi.org/10.1177/0269215508097856

Yuniarwati, W. (2013). Perbedaan Pengaruh
Pemberian Aquatic Exercise Therapy dengan Land Exercise Therapy Terhadap Peningkatan Keseimbangan Statis dan Dinamis Lansia. Journal of Chemical Information and Modeling, 53(9), 16891699.

https://doi.org/10.1017/CBO9781107415324 .004 